Check for updates

The BMJ

Cite this as: $B M J$ 2021;372:n548 http://dx.doi.org/10.1136/bmj.n548 Published: 24 February 2021

\section{Covid-19: GPs could get extra funding to boost vaccine uptake in hard-to-reach groups}

\author{
Gareth lacobucci
}

General practices could be offered "additional discretionary payments" to improve uptake of the covid-19 vaccine in hard-to-reach groups such as deprived and minority ethnic communities.

An update to the national covid-19 enhanced service, ${ }^{1}$ published on 22 February, said that NHS England "may make additional discretionary payments available to GP practices to support the delivery of or incentivise vaccinations in particular seldom heard groups in exceptional circumstances.”

The changes, which have been agreed with the BMA's General Practitioners Committee, come amid concerns about the gap between different patient groups in terms of vaccine uptake, as emerging evidence ${ }^{23}$ shows that uptake is lower among ethnic minority patients.

NHS England said that details of additional payments would be made available on its website (https://www.england.nhs.uk/coronavirus/covid-19vaccinationprogramme/primary-care-guidance/).

Sam Everington, a GP in Bromley-by-Bow in east London and chair of the Tower Hamlets Clinical Commissioning Group, said that, in addition to the extra funding, vaccines should be distributed to all general practices in deprived areas-not just designated sites-to reach more people. He cited GPs' success locally in vaccinating housebound patients when all practices were involved.

"We have a 95\% vaccination rate among housebound people, which is stunning, and that has happened when every general practice is involved in the vaccination programme," he told The BMJ. "There is a very clear solution, and that is to bring vaccination down to every practice in areas like ours where you've got this big difference between the communities.

People respond much better to the GPs and nurses that they know."

\section{Delivering vaccines}

As of 24 February, said Everington, $87 \%$ of white adults aged over 70 in Tower Hamlets had been vaccinated, compared with only $76 \%$ in the Asian community and $62 \%$ in the black community. This variation concerned him, he said, because the way the covid vaccination system was being coordinated in England was "institutionally discriminating against deprived groups.”

He added, "Big vaccination sites are invariably further away from people's homes. People may not have a car or may not be able to travel for medical reasons. We need the vaccine delivered like the flu vaccine to surgeries. I want every practice to be doing it.”
Earlier this week the Runnymede Trust, a race equality think tank, called for vaccines to be offered door to door in deprived and minority ethnic communities. ${ }^{4}$

And the government, in a document published this week setting out its covid-19 plan and road map for spring 2021,5 said that it wanted to ensure that "no one is left behind" in vaccination.

It said, "There are early signs of lower vaccine uptake in lower income and some ethnic minority groups which the government is taking steps to address. Surveys have found that there is higher vaccine hesitancy in some Black and Asian communities, hence the need to encourage uptake in these groups specifically."

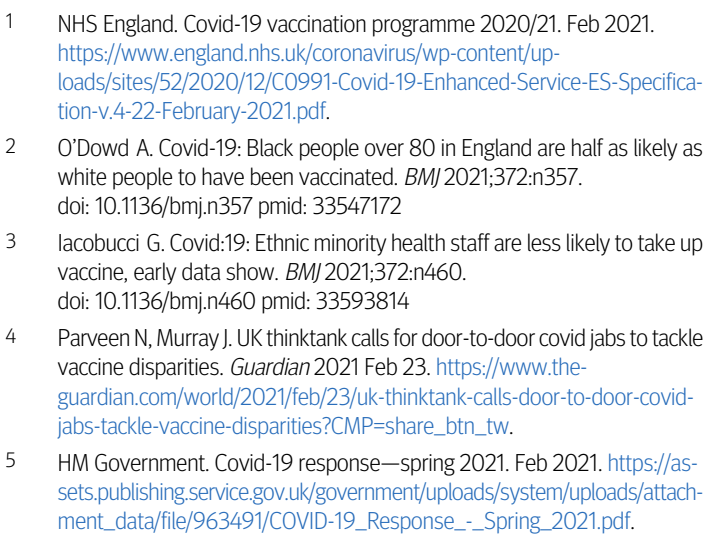

2 O'Dowd A. Covid-19: Black people over 80 in England are half as likely as white people to have been vaccinated. BM/2021;372:n357. doi: 10.1136/bmj.n357 pmid: 33547172

3 lacobucci G. Covid:19: Ethnic minority health staff are less likely to take up vaccine, early data show. BMJ2021;372:n460 doi: 10.1136/bmj.n460 pmid: 33593814

4 Parveen N, Murray J. UK thinktank calls for door-to-door covid jabs to tackle vaccine disparities. Guardian 2021 Feb 23. https://www.theguardian.com/world/2021/feb/23/uk-thinktank-calls-door-to-door-covidjabs-tackle-vaccine-disparities?CMP=share_btn_tw.

$5 \quad$ HM Government. Covid-19 response-spring 2021. Feb 2021. https://assets.publishing.service.gov.uk/government/uploads/system/uploads/attachment_data/file/963491/COVID-19_Response_-_Spring_2021.pdf.

This article is made freely available for use in accordance with BMJ's website terms and conditions for the duration of the covid-19 pandemic or until otherwise determined by BMJ. You may use, download and print the article for any lawful, non-commercial purpose (including text and data mining) provided that all copyright notices and trade marks are retained. 